\title{
Group Lending Model under Sequential Moves
}

\author{
Mahito Okura \\ Faculty of Economics, Nagasaki University, Japan \\ 4-2-1, Katafuchi, Nagasaki, 850-8506 Japan \\ E-mail: okura@nagasaki-u-ac.jp
}

Wei Zhang (Corresponding author)

School of Economics, Beijing Technology and Business University, China

No.33, Fucheng Road, Haidian District, Beijing, 100048 China

E-mail: zhangwei@th.btbu.edu.cn

Received: March 2, 2012

doi:10.5539/ijef.v4n5p146
Accepted: March 23, 2012

Published: May 1, 2012

URL: http://dx.doi.org/10.5539/ijef.v4n5p146

\begin{abstract}
We build a simple dynamic model to investigate the sequential group lending's ability to resolve the ex-ante moral hazard and under-monitoring problems among group members in comparison with simultaneous group lending. We found that the interest rates proposed by the lender are critical to the analytical results. If the interest rate is under certain parameter conditions, both the leader member and the follower member in sequential lending choose higher working effort levels even with the presence of lower peer monitoring in the second period. In this case, the arrangement of sequential lending is beneficial for mitigating the ex-ante moral hazard and under-monitoring problems. If the interest rate is higher than a level with certain parameter configurations, the leader member chooses higher working and monitoring effort levels, whereas the follower member chooses lower working and monitoring effort levels. We also found that the repayment rate in the sequential lending model is higher than that in the simultaneous lending model.
\end{abstract}

Keywords: Group lending, Ex-ante moral hazard, Sequential moves

\section{Introduction}

It is common knowledge that information asymmetries between the lender and poor borrowers, coupled with the lack of conventional collateral of the poor, are the key reasons why credit markets fail for the poor (Simtowe and Zeller, 2006). However, in the past three decades, the group lending programs of Grameen Bank of Bangladesh and Banco Solidario (Bancosol) of Bolivia, as well as other similar microfinance institutions (MFIs), have succeeded in "being able to reach the poor and realizing high repayment performance" (Mehrteab, 2005, p.1) (Note 1). This success has motivated economics theorists to undertake a significant amount of economic research focusing on explaining how and why group lending works in such an information-intensive and enforcement-intensive environment. In this context, most studies have attributed the success to the ability of the so-called group lending contract - which "exploits new contractual structures and organizational forms that reduce the riskiness and costs of making small, uncollateralized loans" (Morduch, 1998, p.1) - to overcome asymmetric information problems, namely, adverse selection, ex-ante moral hazard and ex-post moral hazard, as well as limited enforcement (Note 2).

The basic idea of group lending is that borrowers who can not provide conventional collateral organize themselves into groups in which members are mutually liable for each other's repayments (joint liability $(J L)$ ), even though loans are made to individuals. If the entire group debt is not paid in full — referred to as collective default - the entire group will be denied access to future financing by the lender, until other members repay on behalf of the defaulter (non-refinancing threat (NRT) under renewal contingent discipline). Another distinguishing feature of group lending is sequential lending within the group: The loan delivery process continues in turn as long as those who first received loans repay on time. In the Grameen Bank system, two members of a five-person group are given the first loans and their repayment performance is observed for one or two months. If their repayment performance is deemed satisfactory, the next two get loans. Finally, the fifth member gets his/her loan if the repayment performance of the previous four borrowers is satisfactory. In principle, if a member defaults, all five will be denied future credit. Obviously, NRT is the key factor behind "sequential lending within the group". By employing these mechanisms, 
group lending finds "a way to combine the banks' resources with the local information and cost advantages of informal credit” (Armendáriz de Aghion and Morduch, 2005, p. 8).

Among the most notable ex-ante moral hazard and peer monitoring theories are models built by Stiglitz (1990), and Ghatak and Guinnane (1999). Stiglitz (1990) provided an early treatment of group lending to show how peer monitoring can be used to mitigate ex-ante moral hazard: Under individual liability lending, the form of limited liability - the borrower does not offer collateral and repays the loan only when his/her project succeeds - can encourage the borrower to take risky decisions that increase the probability of default. However, under group lending, the arrangements that group members are mutually liable for each other's repayments and those who succeed have to repay a failed partner's debt obligation give borrowers an incentive to make safe decisions. More importantly, JL creates an incentive for group members to monitor each other's project choices to ensure that partners make safe decisions that protect the borrower from repayment problems. Consequently, group lending mitigates ex-ante moral hazard behavior of the individual group member and enhances repayment rates. In Stiglitz (1990), group members have better information about each other than the lender does and peer monitoring is cheaper than direct monitoring by the lender; therefore, theoretically, group lending leads to greater monitoring which mitigates ex-ante moral hazard.

Based on Stiglitz (1990), Ghatak and Guinnane (1999) developed a modified model to show how JL and peer monitoring can mitigate ex-ante moral hazard with respect to the borrower' s working effort. Their model revealed that when group members decide on working effort non-cooperatively, group lending achieves the same equilibrium individual working effort as individual liability lending; however, when group members act cooperatively, group lending achieves equilibrium individual working effort that compares favorably to that under individual liability lending (Note 3).

Although Stiglitz (1990) and Ghatak and Guinnane (1999) have identified the importance of the incentive JL creates in group lending contracts, the dynamic incentive of NRT has escaped their notice. The individual's motive to avoid the negative consequences of being denied access to future financing has significant effects on a borrower's behaviors (Note 4) and hence giving NRT its due due importance in the economic analysis will allow us to better understand the working of group lending. As a response to Stiglitz (1990) and Ghatak and Guinnane (1999), Zhang (2008a) proposed a theoretical framework inclusive of NRT to establish a benchmark that compares borrowers' working effort levels and loan repayments between individual liability lending and group lending. The results demonstrate that: (1) group lending in which group members decide on working effort non-cooperatively leads to lower equilibrium individual working effort than individual liability lending, and hence exacerbates ex-ante moral hazard; (2) group lending in which group members act cooperatively does not necessarily lead to higher equilibrium individual working effort than individual liability lending; and (3) group lending in which group members act non-cooperatively leads to the same repayment rate as individual liability lending, while group lending in which group members act cooperatively achieves higher repayment rate than individual liability lending.

It is important to note that the analyses of Stiglitz (1990) and Zhang (2008a) rest on costless and perfect peer monitoring and full side contract assumptions (Conning, 2005), in which borrowers within a group can perfectly and costlessly observe each other's actions and enforce any side contracts related to their actions. Such assumptions are separate to the cost of peer monitoring and the difficulty in enforcing side contracts. In reality, monitoring will incur a cost and the enforcement of side contracts in developing countries would be very difficult (Guttman, 2006a); and hence, "[m]onitoring and social sanctions are (......) costly substitutes for collateral" (Conning, 1999, p. 54). Ghatak and Guinnane (1999) further included costly peer monitoring and social sanctions in their model, and simply presented the condition under which the optimal result of Stiglitz (1990) can still be achieved. Similarly, Zhang (2008b) constructed a theoretical framework inclusive of NRT, costly peer monitoring and social sanctions to investigate the determinants of a borrower's ex-ante working effort and ex-ante monitoring effort, as well as the conditions under which group lending performs better in mitigating ex-ante moral hazard and improving economic efficiency.

The studies of Stiglitz (1990), Ghatak and Guinnane (1999), Zhang (2008a and 2008b) and some other papers (e.g., Banerjee et al., 1994) have concluded that lending efficiency is enhanced when borrowers mutually observe each other's actions and impose credible social sanctions on those who shirk. Although a group lending contract can provide monitoring incentives even when monitoring partner's effort incur a cost, a dilemma arises when the advantage of peer monitoring is counteracted by borrowers' collusion. Because the monitoring intensities with which the group members choose to monitor their peers are strategic complements-i.e., the greater the monitoring effort the partner exerts, the greater the monitoring effort the borrower will exert and vice versa (Zhang, 2008b) - group lending will become ineffective when the cost of monitoring is too high and/or the payoffs from investing in the decisions to monitor and to be diligent subsequently are not high enough; in such cases, group 
members may collude on the decision to monitor by not monitoring at all, and hence save the cost of monitoring and obtain the non-monitored private benefits.

Some recent papers (e.g. Chowdury, 2005; Aniket, 2007) have argued that sequential lending within a group can be an instrument to resolve the problem of borrowers' collusion in monitoring (Note 5). Chowdury (2005) found that in a costly monitoring setup, sequential lending enhances the incentive for peer monitoring and may mitigate the under-monitoring problem even in the absence of joint liability (Note 6). Aniket (2007) concluded that sequential lending makes collusion among group members impossible by separating the borrower's effort and monitoring decisions. However, Chowdury (2005) and Aniket (2007) have relatively neglected other features of group lending, namely, NRT and social sanctions. In contrast to Chowdury (2005) and Aniket (2007), we seek to develop a framework inclusive of all these incentive mechanisms to investigate the sequential group lending's ability to resolve the ex-ante moral hazard and under-monitoring problems among group members in comparison with simultaneous group-lending.

The rest of this paper is organized as follows. In Section 2, we analyze simultaneous lending. Section 3 develops the sequential lending model. In Section 4, we compare the abilities of simultaneous and sequential group lending to encourage a borrower's working and monitoring efforts, and to encourage repayment. Concluding remarks are presented in Section 5.

\section{Simultaneous Group Lending}

For simplicity, we restrict the model to a group involving two members (A and B). They make their investments and make efforts to help the investments succeed independently. $p_{i} \in[0,1]$ (where $i \in\{A, B\}$ ) represents the level of effort and success probability for member $i$ 's investment. The effort cost function is quadratic and it is assumed to be specified by $(\alpha / 2) p_{i}^{2}$ where $\alpha>0$. The benefit of this investment is represented by $Y>0$.

A group lending contract is described as $(R, A)$, where $R$ is the pre-specified gross interest rate and $A \in(0, R]$ is the JL payment, i.e., the portion of the debt obligation of the failed member for which the successful one is liable. $A$ measures the degree of $\mathrm{JL}$ and it is decided by the lender. Members make efforts to succeed independently but they are jointly liable for the entire group loan. If one member succeeds and the other member fails, the former has to repay his/her individual liability component $R$ plus an additional JL component $A$. Assuming that $Y>R$ since borrowers are assumed to have no wealth to provided as collateral and then limited liability requires that a borrower can not be forced to pay more than what his/her project yields. For analytical convenience, we assume that borrowers undertake full joint liability, i.e., $A=R$ (Note 7).

When both members succeed, the lender will extend the second-period credit and both members can get benefit $V>0$ from the future financing. In contrast, if both members fail, they will not get this benefit because they can not get future credit from the lender. In the case of "one succeeds, one fails", the successful member repays the failed partner's debt obligation on his/her behalf in order to maintain the credit facility. We assume that if the successful member chooses to default strategically, the failed member will report the partner's action to the lender because he/she loses the future benefit. In this case, the successful member has to pay $R$ to the lender, and the incentive compatibility constraint, where the successful member is always willing to repay for the failed member, has to be assumed as $Y-R \leq Y-R-R+V \Rightarrow R \leq V$. The left-hand side of this equation represents the benefit when a successful member chooses strategic default, while the right-hand side of this equation represents the benefit when a successful member does not choose strategic default and proceeds to the second period.

The arrangements of group lending create incentives for the two group members to monitor each other's effort choices to ensure that the partner works hard, thereby avoiding having to repay for a failed partner. After disbursement of the loan in the first period, the two members will then agree on a level of effort and an individual monitoring level. Suppose that if a member chooses a level of monitoring effort $m \in[0,1]$, he/she can observe the true action taken by his/her partner with probability $m$, while he/she receives a completely uninformative signal with probability $1-m$. If the action undertaken by the partner is different to that agreed on, the monitoring member will impose a non-monetary punishment $W>0$ on the partner and he/she can get some monetary and/or non-monetary value, represented by $\gamma W$ where $\gamma \in(0,1)$. The monitoring cost function is quadratic and it is assumed to be specified by $(\beta / 2) m_{i}^{2}$ where $\beta>0$.

If both members jointly choose their effort level, represented by $p$, to maximize the social surplus, the equilibrium effort level can be derived from the following maximization problem:

$$
\text { Max } p Y-\frac{\alpha}{2} p^{2} \text {. }
$$


Then, $p=Y / \alpha$ is the joint effort level that maximizes the social surplus. To guarantee a value in the range of $[0,1]$, we assume $\alpha \geq Y$.

The expected payoff of member A, which is denoted by $E_{A}$, is

$$
E_{A}=p_{A} p_{B}(Y-R)+\left[1-\left(1-p_{A}\right)\left(1-p_{B}\right)\right] V-\left(1-p_{A}\right) m_{B} W-\frac{\beta}{2} m_{A}^{2}+\left(1-p_{B}\right) m_{A} \gamma W-\frac{\alpha}{2} p_{A}{ }^{2},
$$

where $\left(1-p_{B}\right) m_{A} \gamma W$ is a non-monetary value - which may take the form of "free labor services or services of agricultural implements" (Ghatak, 2000)—that A gets from B when A discovers B's non-diligence.

This game is dynamic and it consists of the following two stages:

First stage: the two members choose their own effort levels simultaneously.

Second stage: the two members choose their own monitoring levels simultaneously.

Thus, to derive the equilibrium (sub-game perfect equilibrium), we have to consider the second stage before the first stage.

Consider the second stage. Both members want to choose their own monitoring levels to maximize their expected payoffs. Thus, each first-order condition is

$$
\frac{\partial E_{A}}{\partial m_{A}}=-\beta m_{A}+\left(1-p_{B}\right) \gamma W=0 \Rightarrow m_{A}=\frac{\left(1-p_{B}\right) \gamma W}{\beta} .
$$

Then,

$$
m_{A}^{*}=\frac{\left(1-p_{B}\right) \gamma W}{\beta},
$$

where the asterisk indicates the equilibrium value. Next, consider the first stage. Using equation (4), equation (2) can be rewritten as follows:

$$
E_{A}=p_{A} p_{B}(Y-R)+\left(p_{A}+p_{B}-p_{A} p_{B}\right) V-\frac{\left(1-p_{A}\right)^{2} \gamma W^{2}}{\beta}+\frac{\left(1-p_{B}\right)^{2} \gamma^{2} W^{2}}{2 \beta}-\frac{\alpha}{2} p_{A}{ }^{2} .
$$

From equation (5), each first-order condition, which represents the best response function, is

$$
\frac{\partial E_{A}}{\partial p_{A}}=p_{B}(Y-R-V)+V+\frac{2 \gamma W^{2}}{\beta}\left(\frac{2 \gamma W^{2}}{\beta}+\alpha\right) p_{A}=0 .
$$

From equation (6), both equilibrium effort levels are derived as follows:

$$
p_{A}^{*}=p_{B}^{*}=\frac{\beta V+2 \gamma W^{2}}{(R+V+\alpha-Y) \beta+2 \gamma W^{2}} .
$$

\section{Sequential Group Lending}

In this section, we consider a sequential group lending model. Without loss of generality, we assume that member A is the leader and member B is the follower because both members are symmetric. The timing of lending is described as follows.

In the first period, member A receives the first-period loan from the lender and chooses effort level $p_{A}$, and member B chooses monitoring level $m_{B}$. If member A fails, both members will be denied future credit and the game is terminated. If member A succeeds, he/she pays $R$ to the lender and gets $Y-R$. The game will continue and member $\mathrm{B}$ will get the first-period loan.

In the second period, member $\mathrm{B}$ is given the first-period loan by the lender and chooses effort level $p_{B}$ and member A chooses monitoring level $m_{A}$. If member B succeeds, he/she pays $R$ to the lender and gets $Y-R$. In contrast, if $\mathrm{B}$ fails, the game is terminated.

The two expected payoffs are written as follows:

$$
\hat{E}_{A}=\hat{p}_{A}\left[\hat{p}_{B}(Y-R)+V-\frac{\beta}{2} \hat{m}_{A}{ }^{2}+\left(1-\hat{p}_{B}\right) \hat{m}_{A} \gamma W\right]-\left(1-\hat{p}_{A}\right) \hat{m}_{B} W-\frac{\alpha}{2} \hat{p}_{A}{ }^{2},
$$




$$
\hat{E}_{B}=\hat{p}_{A}\left[\hat{p}_{B}(Y-R)+V-\left(1-\hat{p}_{B}\right) \hat{m}_{A} W-\frac{\alpha}{2} \hat{p}_{B}{ }^{2}\right]+\left(1-\hat{p}_{A}\right) \hat{m}_{B} \gamma W-\frac{\beta}{2} \hat{m}_{B}{ }^{2},
$$

where the hat indicates variables in the sequential lending model. From the game structure, member A chooses $\hat{p}_{A}$ in the first round and $\hat{m}_{A}$ in the fourth round. In contrast, member B chooses $\hat{m}_{B}$ in the second round and $\hat{p}_{B}$ in the third round. Thus, the four equilibrium values can be derived by backward induction.

First, consider the computation of $\hat{m}_{A}$. The first-order condition with respect to $\hat{m}_{A}$ is

$$
\frac{\partial \hat{E}_{A}}{\partial \hat{m}_{A}}=-\hat{p}_{A}\left[\beta \hat{m}_{A}-\left(1-\hat{p}_{B}\right) \gamma W\right]
$$

Then, the optimal monitoring level of member A can be derived as

$$
\hat{m}_{A}^{*}=\frac{\left(1-\hat{p}_{B}\right) \gamma W}{\beta}
$$

Second, consider the computation of $\hat{p}_{B}$. Substituting equation (11) into equation (9), we obtain

$$
\hat{E}_{B}=\hat{p}_{A}\left[\hat{p}_{B}(Y-R)+V-\frac{\left(1-\hat{p}_{B}\right)^{2} \gamma W^{2}}{\beta}-\frac{\alpha}{2} \hat{p}_{B}{ }^{2}\right]+\left(1-\hat{p}_{A}\right) \hat{m}_{B} \gamma W-\frac{\beta}{2} \hat{m}_{B}{ }^{2} .
$$

The first-order condition with respect to $p_{B}$ is

$$
\frac{\partial \hat{E}_{B}}{\partial \hat{p}_{B}}=\hat{p}_{A}\left[Y-R+\frac{2\left(1-\hat{p}_{B}\right) \gamma W^{2}}{\beta}-\hat{p}_{B} \alpha\right]=0 .
$$

Then,

$$
\hat{p}_{B}^{*}=\frac{\beta(Y-R)+2 \gamma W^{2}}{\alpha \beta+2 \gamma W^{2}} .
$$

Third, consider the computation of $m_{B}$. Substituting equation (14) into equation (12), we obtain

$$
\hat{E}_{B}=\hat{p}_{A}\left[\hat{p}_{B}{ }^{*}(Y-R)+V-\left(1-\hat{p}_{B}{ }^{*}\right) \hat{m}_{A}{ }^{*} W-\frac{\alpha}{2} \hat{p}_{B}{ }^{* 2}\right]+\left(1-\hat{p}_{A}\right) \hat{m}_{B} \gamma W-\frac{\beta}{2} \hat{m}_{B}{ }^{2},
$$

from which we can easily derive the first-order condition with respect to $\hat{m}_{B}$ as follows:

$$
\frac{\partial \hat{E}_{B}}{\partial \hat{m}_{B}}=-\beta \hat{m}_{B}+\left(1-\hat{p}_{A}\right) \gamma W=0 .
$$

Then, the optimal level of $\hat{m}_{B}$ is represented by

$$
\hat{m}_{B}^{*}=\frac{\left(1-\hat{p}_{A}\right) \gamma W}{\beta} .
$$

Last, we consider the computation of $\hat{p}_{A}$. Substituting equations (11), (14), and (17) into equation (8), we show

$$
\hat{E}_{A}=\hat{p}_{A}\left[\hat{p}_{B}{ }^{*}(Y-R)+V-\frac{\beta}{2} \hat{m}_{A}^{* 2}+\left(1-\hat{p}_{B}{ }^{*}\right) \hat{m}_{A}{ }^{*} \gamma W\right]-\left(1-\hat{p}_{A}\right) \hat{m}_{B}^{*} W-\frac{\alpha}{2} \hat{p}_{A}{ }^{2} .
$$

For simplicity of the expression, we define

$$
\Omega \equiv \hat{p}_{B}^{*}(Y-R)+V-\frac{\beta}{2} \hat{m}_{A}^{* 2}+\left(1-\hat{p}_{B}^{*}\right) \hat{m}_{A}^{*} \gamma W .
$$

Because $\Omega$ is not function of $\hat{p}_{A}$, the first-order condition with respect to $\hat{p}_{A}$ can be written as

$$
\Omega-\hat{p}_{A} \alpha+\frac{2\left(1-\hat{p}_{A}\right) \gamma W^{2}}{\beta}=0 .
$$


From equation (20), the optimal level of $\hat{p}_{A}$ is

$$
\hat{p}_{A}^{*}=\frac{\beta \Omega+2 \gamma W^{2}}{\alpha \beta+2 \gamma W^{2}} .
$$

\section{Comparing Simultaneous and Sequential Group Lending}

Let us compare two kinds of effort and monitoring levels. It is easy to verify that the forms of the optimal levels of monitoring are the same for the simultaneous and sequential lending models by comparing equation (4) with equations (11) and (17). Furthermore, these equations are monotone decreasing functions of the effort level. Thus, we only compare the two effort levels.

First, consider the effort levels of member $\mathrm{B}$, who is the follower in the sequential lending model. From equations (7) and (14), we simply compute $\hat{p}_{B}{ }^{*}-p_{B}{ }^{*}$ as follows:

$$
\hat{p}_{B}{ }^{*}-p_{B}{ }^{*}=-\frac{(R+V-Y)(R+\alpha-Y) \beta^{2}}{\left(\alpha \beta+2 \gamma W^{2}\right)\left[(R+V+\alpha-Y) \beta+2 \gamma W^{2}\right]} .
$$

There are two distinct cases:

- If $Y>R+V$, we have $\hat{p}_{B}{ }^{*}-p_{B}{ }^{*}>0$. Then member $\mathrm{B}$ chooses a higher effort level in period 2, whereas member A chooses a lower monitoring level, that is, $\hat{m}_{A}{ }^{*}<m_{A}{ }^{*}$.

- If $Y \leq R+V$, we have $\hat{p}_{B}{ }^{*}-p_{B}{ }^{*} \leq 0$. Then member B chooses a lower effort level in period 2, whereas member A chooses a higher monitoring level, that is, $\hat{m}_{A}{ }^{*} \geq m_{A}{ }^{*}$.

Next, consider the effort levels of member $A$, who is the leader in the sequential lending model. Note that $\alpha \beta+2 \gamma W^{2} \leq(R+V+\alpha-Y) \beta+2 \gamma W^{2}$ because $R+V \geq Y$. From equations (7) and (21), we compute $\hat{p}_{A}{ }^{*}-p_{A}{ }^{*}$ as follows:

$$
\begin{gathered}
\hat{p}_{A}{ }^{*}-p_{A}{ }^{*}=\frac{\beta \Omega+2 \gamma W^{2}}{\alpha \beta+2 \gamma W^{2}}-\frac{\beta V+2 \gamma W^{2}}{(R+V+\alpha-Y) \beta+2 \gamma W^{2}} \\
\geq \frac{\beta \Omega+2 \gamma W^{2}}{(R+V+\alpha-Y) \beta+2 \gamma W^{2}}-\frac{\beta V+2 \gamma W^{2}}{(R+V+\alpha-Y) \beta+2 \gamma W^{2}}=\frac{\beta(\Omega-V)}{(R+V+\alpha-Y) \beta+2 \gamma W^{2}} .
\end{gathered}
$$

Furthermore, we find that

$$
\Omega-V=\hat{p}_{B}{ }^{*}(Y-R)-\frac{\beta}{2} \hat{m}_{A}^{* 2}+\left(1-\hat{p}_{B}{ }^{*}\right) \hat{m}_{A}{ }^{*} \gamma W=\hat{p}_{B}{ }^{*}(Y-R)+\frac{\left(1-\hat{p}_{B}^{*}\right)^{2} \gamma^{2} W^{2}}{2 \beta}>0 .
$$

From equations (23) and (24), we show

$$
\hat{p}_{A}{ }^{*}-p_{A}{ }^{*}>0 \Rightarrow \hat{p}_{A}^{*}>p_{A}^{*} \text {. }
$$

Equation (25) indicates that member A chooses a higher effort level in period 2, whereas member B chooses a lower monitoring level, that is, $\hat{m}_{B}{ }^{*}<m_{B}{ }^{*}$.

Then for a given $R$, if $R<Y-V$, both $\mathrm{A}$ and $\mathrm{B}$ choose higher working effort levels and lower monitoring levels in period 2. In this case, sequential lending is beneficial for mitigating ex-ante moral hazard and under-monitoring problems in comparison with simultaneous lending. If $R \geq Y-V$, member $\mathrm{B}$ will choose a lower effort level and member A has to choose a higher monitoring level in period 2. Then the repayment schedule $R$ proposed by the lender is critical to the comparison between sequential lending and simultaneous lending.

We further compare two kinds of repayment rates. It is easy to see that the repayment rates, which are denoted by $\gamma$ in the simultaneous lending model and $\hat{\gamma}$ in the sequential lending model, are as follows:

$$
\begin{gathered}
\gamma=1-\left(1-p_{A}\right)\left(1-p_{B}\right)=2 p_{A}{ }^{*}-p_{B}{ }^{* 2}, \\
\hat{\gamma}=\hat{p}_{A}{ }^{*}+\hat{p}_{B}{ }^{*} .
\end{gathered}
$$

Using equations (7), (14), and (21), we compute $\hat{\gamma}-\gamma$ as follows: 


$$
\begin{aligned}
& \hat{\gamma}-\gamma=\hat{p}_{A}{ }^{*}+\hat{p}_{B}{ }^{*}-2 p_{A}{ }^{*}+p_{A}{ }^{* 2} \\
= & \frac{\beta \Omega+2 \gamma W^{2}}{\alpha \beta+2 \gamma W^{2}}+\frac{\beta(Y-R)+2 \gamma W^{2}}{\alpha \beta+2 \gamma W^{2}}-\frac{2 \beta V+4 \gamma W^{2}}{(R+V+\alpha-Y) \beta+2 \gamma W^{2}}+\left[\frac{\beta V+2 \gamma W^{2}}{(R+V+\alpha-Y) \beta+2 \gamma W^{2}}\right]^{2} \\
> & \frac{\beta(\Omega+Y-R)+4 \gamma W^{2}}{(R+V+\alpha-Y) \beta+2 \gamma W^{2}}-\frac{2 \beta V+4 \gamma W^{2}}{(R+V+\alpha-Y) \beta+2 \gamma W^{2}}+\left[\frac{\beta V+2 \gamma W^{2}}{(R+V+\alpha-Y) \beta+2 \gamma W^{2}}\right]^{2} \\
= & \frac{\beta(\Omega+Y-R-2 V)}{(R+V+\alpha-Y) \beta+2 \gamma W^{2}}+\left[\frac{\beta V+2 \gamma W^{2}}{(R+V+\alpha-Y) \beta+2 \gamma W^{2}}\right]^{2} \\
= & \left.\frac{\beta(\Omega+Y-R-2 V)\left[(R+V+\alpha-Y) \beta+2 \gamma W^{2}\right]}{\left[(R+V+\alpha-Y) \beta+2 \gamma W^{2}\right]^{2}}\right]^{2} \\
> & \frac{\beta(\Omega+Y-R-2 V)(\beta V)}{\left[(R+V+\alpha-Y) \beta+2 \gamma W^{2}\right]^{2}}+\left[\frac{\beta V+2 \gamma W^{2}}{(R+V+\alpha-Y) \beta+2 \gamma W^{2}}\right]^{2} \\
& =\frac{\beta^{2}[V(\Omega-V)+(Y-R) V]}{\left[(R+V+\alpha-Y) \beta+2 \gamma W^{2}\right]^{2}}>0 \Rightarrow \hat{\gamma}>\gamma .
\end{aligned}
$$

Equation (28) indicates that the repayment rate in the sequential lending model is higher than that in the simultaneous lending model.

\section{Concluding Remarks}

In a moral hazard environment with costly peer monitoring, we investigate the sequential group lending's ability to resolve the ex-ante moral hazard and under-monitoring problems among group members in comparison with simultaneous group lending. The results show that when credit is allocated to group members simultaneously, the borrowers make their decisions regarding monitoring and effort collectively. Alternatively, when credit is disbursed sequentially within the group, i.e., the second borrower gets a loan only if the first borrower succeeds and repays his/her debt, the borrower's effort and monitoring decisions are temporally separated. The interest rates proposed by the lender are critical to the comparison between simultaneous and sequential group lending in mitigating ex-ante moral hazard and under-monitoring problems. If the interest rate is under certain parameter conditions, both the leader member and the follower member in sequential lending choose higher working effort levels even with the presence of lower peer monitoring in the second period. If the interest rate is higher than a level with certain parameter configurations, the leader in sequential lending chooses higher working and monitoring effort levels, whereas the follower member chooses lower working and monitoring effort levels. Furthermore, we found that the repayment rate in the sequential lending model is higher than that in the simultaneous lending model. The findings in this paper are to some extent different to the conclusions of the existing literature that sequential lending can help in mitigating the moral hazard and under-monitoring problems. The reason is that we incorporate the relatively neglected features of group lending, NRT and social sanctions, in our model, which is not only helpful to better understand the working of group lending and provide guidance for empirical studies, but also beneficial for identifying appropriate policies and scheme designs.

Finally, although many MFIs, such as Grameen Bank and many of its replicators, have widely adopted sequential lending in their programs and the theoretical literature has predicted positive impact of the mechanism of sequential lending on mitigating moral hazard and encouraging repayment, theoretical predictions has been seldom explored by empirical studies. The reason may be that because the theoretical models take different stands on the underlying hypothesized economic environments from the empirical environments and the "filed experiments, while feasible, are difficult to implement and sometimes come at the cost of some loss of experimental control" (Cason et al., 2012, p.193, Note 5). Cason et al. (2012) took a laboratory experiments approach to deal with this issue and they found that contrary to theoretical predictions, simultaneous and sequential lending rules provide equivalent empirical performance. The theoretical propositions are needed to be examined and refined by more empirical evidence, which provides a room for our future research. 


\section{References}

Ahlin, C., \& Townsend, R. M. (2007a). Using repayment data to test across models of joint liability lending. The Economic Journal, 117 (517), F11-F51. http://dx.doi.org/10.1111/j.1468-0297.2007.02014.x

Ahlin, C., \& Townsend, R. M. (2007b). Selection into and across credit contracts: Theory and field research. Journal of Econometrics, 136 (2), 665-698. http://dx.doi.org/10.1016/j.jeconom.2005.11.013

Aniket, K. (2007). Sequential group lending with moral hazard. ESE Discussion Paper No. 136, Edinburgh School of Economics, University of Edinburgh. http://www.aniket.co.uk/research/sql.pdf

Armendáriz de Aghion, B. (1999). On the design of a credit agreement with peer monitoring. Journal of Development Economics, 60(1), 79-104. http://dx.doi.org/10.1016/S0304-3878(99)00037-1

Armendáriz de Aghion, B., \& Gollier, C. (2000). Peer group formation in an adverse selection model. Economic Journal, 110(465), 632-643. http://dx.doi.org/10.1111/1468-0297.00557

Armendáriz de Aghion, B., \& Morduch, J. (2000). Microfinance beyond group lending. The Economics of Transition, 8(2), 401-420. http://dx.doi.org/10.1111/1468-0351.00049

Armendáriz de Aghion, B., \& Morduch, J. (2005). The Economics of Microfinance. Cambridge, MA: MIT Press.

Banerjee, A.V., Besley, T., \& Guinnane, T.W. (1994). Thy neigbor's keeper: the design of a credit cooperative with theory and a test. Quarterly Journal of Economics, 109 (2), 491-515. http://dx.doi.org/10.2307/2118471

Besley, T., \& Coate, S. (1995). Group lending, repayment incentives and social collateral. Journal of Development Economics, 46(1), 1-18. http://dx.doi.org/10.1016/0304-3878(94)00045-E

Cason, T.N., Gangadharan, L., \& Maitra, P. (2012). Moral hazard and peer monitoring in a laboratory microfinance experiment. Journal of Economic Behavior and Organization, 82, 192-209. http://dx.doi.org/10.1016/j.jebo.2012.02.003

Cassar, A., Crowley, L., \& Wydick, B. (2007). The effect of social capital on group loan repayment: Evidence from field experiments. The Economic Journal, 117(517), F85-F106. http://dx.doi.org/10.1111/j.1468-0297.2007.02016.x

Chowdhury, R.P. (2005). Group lending: Sequential financing, lender monitoring and joint liability. Journal of Development Economics, 77(2), 415-439.http://dx.doi.org/10.1016/j.jdeveco.2004.05.005

Chowdhury, R.P. (2007). Group lending with sequential financing, contingent renewal and social capital. Journal of Development Economics, 84(1), 487-506. http://dx.doi.org/10.1016/j.jdeveco.2006.01.001

Conning, J. (1996). Group lending, moral hazard, and the creation of social collateral. Working Paper, Center for Institutional Reform and the Informal Sector, University of Maryland at College Park. http://www.iris.umd.edu/download.aspx?ID=77e289bb-512d-4167-88f9-72ea146f7c55

Conning, J. (1999). Outreach, sustainability and leverage in monitored and peer-monitored lending. Journal of Development Economics, 60(1), 51-77. http://dx.doi.org/10.1016/S0304-3878(99)00036-X

Conning, J. (2005). Monitoring by peers or by delegates? Joint liability loans and moral hazard. Hunter College $\begin{array}{lllll}\text { Department of } & \text { Economics } & \text { Working } & & \end{array}$ http://arrow.hunter.cuny.edu/research/papers/HunterEconWP407.pdf

Cull, R., Asli Demirgüç-Kunt, A., \& Morduch, J. (2007). Financial performance and outreach: A global analysis of lending microbanks. The Economic Journal, 117(517), F107-F133. http://dx.doi.org/10.1111/j.1468-0297.2007.02017.x

Ghatak, M. (1999). Group lending, local information and peer selection. Journal of Development Economics, 60(1), 27-50. http://dx.doi.org/10.1016/S0304-3878(99)00035-8

Ghatak, M. (2000). Screening by the company you keep: Joint liability lending and the peer selection effect. Economic Journal, 110(4), 601-631. http://dx.doi.org/10.1111/1468-0297.00556

Ghatak, M., \& Guinnane, T.W. (1999). The economics of lending with joint liability: Theory and practice. Journal of Development Economics, 60(2), 195-228. http://dx.doi.org/10.1016/S0304-3878(99)00041-3

Giné, X., \& Karlan, D. (2006). Group versus individual liability: A field experiment in the Philippines. Working Papers 940, Economic Growth Center, Yale University. http://www.econ.yale.edu/growth_pdf/cdp940.pdf

Guttman, J.M. (2006a). Repayment performance in microcredit programs: A survey. Working Paper No. 2006-WP-01, Networks Financial Institute, Indianapolis, http://papers.ssrn.com/sol3/papers.cfm?abstract_id=924363 
Guttman, J.M. (2006b). Moral hazard and repayment performance under group lending. Working Paper No. 2006-WP-03, Networks Financial Institute, Indianapolis, http://papers.ssrn.com/sol3/papers.cfm?abstract_id=921904

Guttman, J.M. (2008). Assortative matching, adverse selection, and group lending. Journal of Development Economics, 87(1), 51-56. http://dx.doi.org/10.1016/j.jdeveco.2007.06.002

Karlan, D.S. (2007). Social connections and group banking. The Economic Journal, 117 (517), F52-F84. http://dx.doi.org/10.1111/j.1468-0297.2007.02015.x

Laffont, J.J., \& N'Guessan, T. (2000). Group lending with adverse selection. European Economic Review, 44(4-6), 773-784. http://dx.doi.org/10.1016/S0014-2921(99)00041-0

Laffont, J.J., \& Rey, P (2003). Collusion and group lending with moral hazard. IDEI Working Papers, No. 122, Institut d'Économie Industrielle $\quad$ Toulouse. http://www.krannert.purdue.edu/programs/phd/Working-paper-series/Year-2008/1208.pdf

Lensink, R., \& Mehrteab, H.T.(2003). Risk behavior and group formation in microcredit groups in Eritrea. CREDIT Research Paper No. 03/02, Research Institute SOM, University of Groningen. http://papers.ssrn.com/sol3/papers.cfm?abstract_id $=380700$

Mehrteab, H.T. (2005). Adverse selection and moral hazard in group-based lending: Evidence from Eritrea. Ph.D. Dissertation of the University of Groningen. http://irs.ub.rug.nl/ppn/271447184

Morduch, J. (1998). Does microfinance really help the Poor? New evidence from flagship programs in Bangladesh. Working Paper, ECARES, Princeton University, Woodrow Wilson School of Public and International Affairs, Research Program in Development http://rpds.princeton.edu/rpds/papers/pdfs/morduch_microfinance_poor.pdf

Morduch, J. (1999). The microfinance promise. Journal of Economic Literature, 37(4), 1569-1614. http://dx.doi.org/10.1257/jel.37.4.1569

Sadoulet, L. (2000). Equilibrium risk-matching in group lending. Contributed Paper No. 1302, the 8th Econometric Society World Congress, Seattle, Washington, August 2000. http://fmwww.bc.edu/RePEc/es2000/1302.pdf

Sadoulet, L., \& Carpenter, S. (2001). Endogenous matching and risk heterogeneity: Evidence on microcredit group formation in Guatemala. Working Paper, ECARES, Université Libre de Bruxelles.

Simtowe, F., \& Zeller, M. (2006). Determinants of moral hazard in microfinance: Empirical evidence from joint liability lending programs in Malawi. MPRA (Munich Personal RePEc Archive) Paper No.461. http://mpra.ub.uni-muenchen.de/461/

Stiglitz, J.E. (1990). Peer monitoring and credit markets. World Bank Review, 4(3), 351-366. http://dx.doi.org/10.1093/wber/4.3.351

Van Tassel, E. (1999). Group lending under symmetric information. Journal of Development Economics, 60 (1), 3-25. http://dx.doi.org/10.1016/S0304-3878(99)00034-6

Wydick, B. (1999). Can social cohesion be harnessed to repair market failures? Evidence from group lending in Guatemala. Economic Journal, 109(457), 463-475. http://dx.doi.org/10.1111/1468-0297.00457

Zhang, W. (2008a). Ex-ante moral hazard and repayment performance under group lending. Journal of East Asian Studies (Japan), 6. 145-171. http://repository.oai.yamaguchi-u.ac.jp/yunoca/D30/D300006000009.pdf

Zhang, W. (2008b). Adverse selection, ex-ante moral hazard and group lending: Theory and evidence. Ph.D. Dissertation of the Graduate School of East Asian Studies, Yamaguchi University, Japan.

Zhang, W. (2009). Group lending with adverse selection. International Economics and Finance Journal, 4(1-2), 33-58.

http://www.econbiz.de/en/search/detailed-view/doc/Group\%20lending\%20with\%20adverse\%20selection/10009047 797/?no_cache $=1$

\section{Notes}

Note 1. Compared to the subsidized credit programs and other theoretical forms of rural credit, the representative group-based microcredit programs have enjoyed remarkable success reflected by repayment rates often about $95 \%$ (Morduch, 1999).

Note 2. The theoretical explanations generally confirming that group lending leading to higher repayment rates due to more effective of screening, monitoring and enforcement among group members can be roughly categorized into: 
(1) those dealing with joint liability, peer selection and adverse selection problem (e.g. Ghatak 1999 and 2000; Sadoulet, 2000; Van Tassel; 1999; Armendáriz de Aghion and Gollier, 2000; Laffont and N'Guessan 2000; Guttman, 2008; Zhang, 2009), (2) those concerned with joint liability, peer monitoring and ex-ante moral hazard problem (e.g. Stiglitz, 1990; Banerjee et al., 1994; Conning, 1996, 1999 and 2005; Ghatak and Guinnane, 1999; Armendáriz de Aghion and Morduch, 2000; Laffont and Rey, 2003; Chowdhury, 2005; Guttman, 2006b; Aniket, 2007; Cason et al., 2008; Zhang, 2008a and 2008b), and (3) those addressing joint liability, non-refinancing threat, social sanctions, peer monitoring, and ex-post moral hazard problem (e.g. Besley and Coate, 1995; Armendariz de Aghion, 1999). The empirical studies on group lending can be roughly categorized into: (1) those addressing peer matching and group formation (e.g. Sadoulet and Carpenter, 2001; Lensink and Mehrteab, 2003), (2) those exploring the relevance of social capital to repayment performance (e.g. Wydick, 1999; Ahlin and Townsend, 2007a; Cassar et al., 2007; Karlan, 2007), and (3) those concerned with the relative advantages of group lending versus individual liability lending (e.g. Giné and Karlan, 2006; Ahlin and Townsend, 2007a and 2007b; Cull et al., 2007).

Note 3. Banerjee et al. (1994) discussed credit cooperatives, which were common in the late 1890s and the early 1900s in Europe, and they found that German credit cooperatives create similar incentive structures to group-based lending, which induces peer monitoring among borrowers. Furthermore, the monitoring member may impose a penalty on the borrowing member in the case of default, which is helpful in reducing ex-ante moral hazard. Because monitoring by microcredit institutions is assumed to be costly, most theoretical analyses focusing on ex-ante moral hazard in group lending emphasize peer monitoring. In contrast, Conning (1996, 1999 and 2005) examined whether the monitoring by lending institutions or delegated monitoring is as good as or better than peer monitoring at enforcing loan repayment and argued that only when group lending is optimal to individual liability lending do group members have a substantial monitoring and enforcement advantage over outsiders (the delegated monitor or the lender) and when the correlations across borrowers' outputs are not high.

Note 4. Armendáriz de Aghion (1999) investigated the effect of NRT in mitigating ex-post moral hazard (strategic default) and interpreted NRT as a punishment imposed on borrowers who default strategically.

Note 5. Cason et al. (2012) examined this issue by taking a laboratory experiments approach.

Note 6. Chowdhury (2007) focused on sequential financing and contingent renewal, and also examined the efficacy of those two schemes in harnessing social capital.

Note 7. As it is assumed, the lender cannot observe the outcome of a borrower's project, i.e., success or failure, prior to the repayment of the loan. If $A<R$, such that both of them succeed, borrowers within a group may pretend to partly fail and pay $(R+A)$ instead of $2 R$ to the lender. The lender will make a negative profit in such a case. If $A>R$, when one member fails, rather than tell the lender the truth, the two borrowers may collude to tell the lender that they both succeed, and then pay $2 R$ instead of $(R+A)$ to the lender. If $A \neq R$, the lender will never get paid as it expected. Therefore, the optimal and maximum feasible joint liability payment is $A=R$. To make the expression clear, we use $A$ rather than $R$ to denote JL payment in the following analysis. 